\title{
Contribution of the ROS-p53 feedback loop in thuja-induced apoptosis of mammary epithelial carcinoma cells
}

\author{
SHILPI SAHA $^{1 *}$, PUSHPAK BHATTACHARJEE ${ }^{1 *}$, SHRAVANTI MUKHERJEE ${ }^{1}$, \\ MINAKSHI MAZUMDAR ${ }^{1}$, SAMIK CHAKRABORTY ${ }^{1}$, ANIL KHURANA ${ }^{2}$, DEBADATTA NAYAK ${ }^{2}$, \\ RAJKUMAR MANCHANDA ${ }^{2}$, RATHIN CHAKRABARTY ${ }^{3}$, TANYA DAS $^{1}$ and GAURISANKAR SA ${ }^{1}$ \\ ${ }^{1}$ Division of Molecular Medicine, Bose Institute, P1/12, CIT Scheme VIIM, Kolkata 700054; \\ ${ }^{2}$ Central Council for Research in Homeopathy, 61-65 Institutional Area, Janakpuri, New Delhi 110058; \\ ${ }^{3}$ Bholanath Chakrabarty Trust, 5 Subol Koley Lane, Howrah 711101, India
}

Received November 14, 2013; Accepted December 16, 2013

DOI: $10.3892 /$ or.2014.2993

\begin{abstract}
The adverse side-effects associated with chemotherapy during cancer treatment have shifted considerable focus towards therapies that are targeted but devoid of toxic side-effects. In the present study, the antitumorigenic activity of thuja, the bioactive derivative of the medicinal plant Thuja occidentalis, was evaluated, and the molecular mechanisms underlying thuja-induced apoptosis of functional p53-expressing mammary epithelial carcinoma cells were elucidated. Our results showed that thuja successfully induced apoptosis in functional p53-expressing mammary epithelial carcinoma cells. Abrogation of intracellular reactive oxygen species (ROS), prevention of p53-activation, knockdown of p53 or inhibition of its functional activity significantly abridged ROS generation. Notably, under these conditions, thuja-induced breast cancer cell apoptosis was reduced, thereby validating the existence of an ROS-p53 feedback loop. Elucidating this feedback loop revealed bi-phasic ROS generation as a key mediator of thuja-induced apoptosis. The first phase of ROS was instrumental in ensuring activation of p53 via p38MAPK
\end{abstract}

Correspondence to: Professor Gaurisankar Sa or Professor Tanya Das, Division of Molecular Medicine, Bose Institute, P-1/12, CIT Scheme VII M, Kolkata 700 054, India

E-mail: gauri@jcbose.ac.in

E-mail: tanya@jcbose.ac.in

*Contributed equally

Abbreviations: $\mathrm{Bax}, \mathrm{Bcl}-2$ associated $\mathrm{X}$ protein; $\mathrm{Bcl}-2$, B cell lymphoma-2; CAM, complementary and alternative medicine; CsA, cyclosporine A; DAPI, 4',6-diamidino-2-phenylindole dihydrochloride; $\mathrm{DiOC}_{6}$, 3,3-dihexyloxacarbocyanine iodide; MTP, mitochondrial membrane potential; $\mathrm{H}_{2} \mathrm{O}_{2}$, hydrogen peroxide; PBLs, peripheral blood lymphocytes; NAC, $\mathrm{N}$-acetylcysteine; p38MAPK, p38 mitogen activated protein kinase; ROS, reactive oxygen species; siRNA, short-interfering RNA; shRNA, short-hairpin RNA

Key words: apoptosis, Bax, cancer, homeopathy, p38MAPK, p53, ROS, thuja and its nuclear translocation for transactivation of Bax, which induced a second phase of mitochondrial ROS to construct the ROS-p53 feedback loop. Such molecular crosstalk induced mitochondrial changes i) to maintain and amplify the thuja signal in a positive self-regulatory feedback manner; and ii) to promote the mitochondrial death cascade through cytochrome $c$ release and caspase-driven apoptosis. These results open the horizon for developing a targeted therapy by modulating the redox status of functional p53-expressing mammary epithelial carcinoma cells by thuja.

\section{Introduction}

Breast cancer is the most prevalent cancer in women and affects approximately one million women worldwide (1). One out of eight women will develop breast cancer sometime during her life. The higher prevalence of using complementary and alternative medicine (CAM) to treat cancer patients (40-83\%) receiving conventional treatment was recognized due to the adverse toxic side-effects of chemotherapy during breast cancer treatment (2). Among the different CAM regimens, homeopathy, a nearly 200-year-old system of medicine has been shown to alleviate the side-effects of chemotherapy in cancer patients, and homeopathic drugs possess antitumorigenic property $(3,4)$. Unfortunately, scientific studies corroborating these clinical observations are few. There are only a few reports on the mechanism of action of homeopathic drugs in experimental cancers and cell cultures (5-7).

In the present study, we investigated the underlying molecular mechanisms of the antitumorigenic effects of thuja, a promising homeopathic remedy, on breast cancer cells. Thuja, a bioactive derivative of the white cedar tree, Thuja occidentalis, is used in homeopathy for treating polypus type of tumors of the breast, skin and uterus and for other diseases of the skin, blood, gastrointestinal tract, kidney, brain and warty excrescences (8-10). The protective effect of T. occidentalis has also been reported against radiation-induced toxicity in mice (11). Studies have found that thuja has promising cytotoxic effects on Dalton's lymphoma ascites (DLA), Ehrlich ascites carcinoma (EAC) and lung carcinoma L929 cells (12). Dubey and Batra also reported hepatoprotective activities (13) 
and antioxidant activity (14) of thuja in $\mathrm{CCL}_{4}$-treated liver damage in rats. In another study, in vitro treatment with the thujone-rich fraction showed cytotoxic, antiproliferative and apoptosis in A375 melanoma cells (9). Moreover, an in vitro study by Frenkel et al (7) revealed the antitumorigenic effect of thuja on breast cancer cells. However, the underlying mode of action involved in its professed antitumorigenic effects on breast cancer is still largely unidentified and warrants further study. To the best of our knowledge, therefore, this is the first report elucidating the detailed mechanism of action of the antitumorigenic effects of thuja on breast cancer cells.

It has been well established that the development and growth of tumor cells are controlled by complex signaling pathways involved in the regulation of cell death, survival and proliferation. In mammalian cells, the response to cellular stress factors such as DNA damage involves activation of tumor-suppressor p53, which translates stress signals into cell cycle arrest or apoptosis, depending on the balance between pro-apoptotic and antiproliferative genes. Tumor-suppressor p53 being the 'the guardian of the genome' is one of the most frequent targets in the therapy of human tumors (15). Thus, drugs reviving the tumor-suppressor functions of p53 are effective for targeted cancer therapy.

Tumor-suppressor p53 is a redox active transcription factor that organizes and directs cellular responses in the face of a variety of stresses that lead to genomic instability. Evidence suggests that reactive oxygen species (ROS) generated by cells as products or by-products, can function either as signaling molecules in diverse physiological processes or as cellular toxicants (16). Indeed, low levels of ROS have been linked to cellular proliferation and cell cycle progression. This provides an explanation for the pro-oxidant state invariably associated with the transformed phenotype (17). In contrast, higher levels of ROS stimulate multiple death pathways such as typical and atypical apoptosis and necrosis, thereby enhancing therapeutic efficiency. In our research the anti-apoptotic (18) and antimigratory effects of ROS (19) were validated. Recent studies revealed that cellular concentration and distribution of p53 has a distinct cellular function, and that ROS act as both an upstream signal that triggers p53 activation and as a downstream factor that mediates apoptosis (16). Therefore, a novel approach for enhancing therapeutic drug-mediated tumor cell death is effective when drug-induced oxidative stress triggers p53, a redox active transcription factor, to allow efficient execution of drugdependent apoptosis.

The present study investigated the antitumorigenic potential of thuja, a bioactive extract of Thuja occidentalis, commonly known as Arbor vitae or white cedar. Our findings revealed that thuja preferentially induced apoptosis in functional p53-expressing mammary epithelial carcinoma cells sparing normal cells, highlighting the imperative role of ROS in initiating and amplifying the p53-dependent programmed suicide of breast cancer cells. While revealing the detail molecular mechanism, it was found that thuja manipulates the intracellular redox state of functional p53-expressing breast cancer cells in an ROS-p53 feedback loop manner to amplify cell death via the mitochondrial death pathway. In summary, the present study for the first time elucidates the molecular mechanisms underlying the antitumorigenic activity of thuja against breast cancer that may be exploited to achieve efficient and safe tumor regression.

\section{Materials and methods}

Cell culture. Human mammary epithelial carcinoma cell lines, MCF-7 and MDA-MB-231, were obtained from NCCS, India. Peripheral blood collected from healthy human volunteers with informed consent (Institutional Review Board 1382) was centrifuged over Ficoll-Hypaque density gradient (Amersham Pharmacia, Uppsala, Sweden) to obtain total peripheral blood mononuclear cells. Cells were routinely maintained in DMEM supplemented with $10 \%$ heat inactivated fetal bovine serum (Lonza, Portsmouth, NH, USA), L-glutamine ( $2 \mathrm{mM})$, sodium pyruvate $(100 \mathrm{mg} / \mathrm{ml})$, non-essential amino acids $(100 \mathrm{mM})$, streptomycin $(100 \mathrm{mg} / \mathrm{ml})$, penicillin $(50 \mathrm{U} / \mathrm{ml}$; Invitogen, Carlsbad, CA, USA) at $37^{\circ} \mathrm{C}$ in a humidified $5 \% \mathrm{CO}_{2}$ incubator. Cells were maintained in an exponential growth phase for all experiments. Viable cell numbers were determined by trypan blue exclusion test.

Treatment of cells. The different strengths $(6 \mathrm{C}, 30 \mathrm{C}$ and 200C) of placebo and thuja were procured from Hahnemann Publishing Co. Pvt., Ltd. (Kolkata, India) (authorized manufacturing house sanctioned by both GMP and certified by ISO). The drugs procured were colorless, odorless and endotoxin-free. Drugs were stored at room temperature, away from sunlight and vigorously shaken immediately before each treatment. Cells were treated with thuja or placebo of potencies $6 \mathrm{C}$ or $30 \mathrm{C}$ or $200 \mathrm{C}$ at different concentrations $(10,15,20$ and $30 \mu \mathrm{l} / \mathrm{ml})$ for different time-points $(0,6,8,12,24,36$ and $48 \mathrm{~h}$ ) to select the optimum time required for cell killing. To understand the sequence of events leading to apoptosis, cancer cells were treated with mitochondrial pore inhibitor cyclosporine A (CsA) (25 $\mu \mathrm{M}$; Merck, Darmstadt, Germany) for $1 \mathrm{~h}$ prior to incubation with thuja. For transcriptional blockage of p53, cells were treated with pifithrin- $\alpha$ (30 $\mu \mathrm{M}$; Sigma). NAC ( $40 \mathrm{mM}$; Sigma) treatment was carried out for $1 \mathrm{~h}$ prior to incubation with thuja for pharmacological inhibition of ROS while $\mathrm{H}_{2} \mathrm{O}_{2}(0.5 \mathrm{mM}$; Sigma) treatment was applied for ROS enhancement.

Flow cytometry. For the determination of cell death, cells were stained with 7AAD and Annexin V-PE and analyzed by flow cytometry (FACSCalibur; BD Biosciences, San Jose, CA, USA). Electronic compensation of the instrument was conducted to exclude overlapping of the emission spectra. A total of 10,000 events were acquired for analysis using CellQuest software (BD Biosciences) (20). For the assessment of mitochondrial transmembrane potential, cells were loaded with potential-sensitive dye 3,3-dihexyloxacarbocyanine iodide $\left(\mathrm{DiOC}_{6}\right.$; Merck) during the last $30 \mathrm{~min}$ of treatment at $37^{\circ} \mathrm{C}$ in the dark. Fluorescence of retained $\mathrm{DiOC}_{6}$ was determined by flow cytometry using logarithmic amplification by CellQuest software (21).

Assessment of ROS. For detection of intracellular ROS, the untreated and thuja-treated cells were incubated during the last $20 \mathrm{~min}$ at $37^{\circ} \mathrm{C}$ in the dark with $10 \mu \mathrm{M}$ of dichlorofluorescein diacetate (DCF-DA; Sigma). DCF fluorescence was measured by flow cytometry and subjected to analysis using CellQuest 3.2 software. The probe was excited at $488 \mathrm{~nm}$ and emission was measured through a $530 \mathrm{~nm}$ band-pass filter. For 
confocal microscopy a Leica fluorescence microscope DM 900 was used to visualize the images of thuja-treated cells incubated with DCF-DA $(10 \mu \mathrm{M})$. DCF-DA is colorless and non-fluorescent until both of the acetate groups are hydrolyzed and the products are subsequently oxidized to fluorescein derivatives $\left(\mathrm{H}_{2} \mathrm{DCFDA}\right)$. Digital images were captured with a cool $\left(-25^{\circ} \mathrm{C}\right)$ charged coupled device $(\mathrm{CCD})$ camera (Princeton Instruments) controlled with the Andor iQ BioImaging software (BT, London, UK) (19).

Fluorescence imaging. Chromatin condensation and nuclear fragmentation were analyzed using a standard protocol. Briefly, cells were grown on coverslips, fixed with $3 \%$ p-formaldehyde for $10 \mathrm{~min}$ and then permeabilized with $0.1 \%$ Triton $\mathrm{X}-100$ for $5 \mathrm{~min}$. Cells were then incubated with 4'6-diamidino-2-phenylindole (DAPI; BD Pharmingen, San Jose, CA, USA). The morphology of the cell nuclei was visualized using a fluorescence microscope (Leitz microscope fitted with epifluorescence illuminator through a x60 aperture oil immersion lens; Carl Zeiss, Oberkochen, Germany). For fluorescent imaging, cells growing on a coverslip were fixed with 3\% p-formaldehyde and were stained with the anti-p53 antibody (Santa Cruz Biotechnology, Santa Cruz, CA, USA), after permeabilization with Triton X-100, followed by addition of the TRITC-conjugated secondary antibody and visualized with a confocal microscope (Carl Zeiss).

Plasmids, siRNA and transfections. MCF-7-Dn-p53 was derived from MCF-7 cells through an adenoviral vector expression system expressing dominant-negative p53 (Dn-p53) under the control of a cytomegalovirus promoter (Clontech). Similarly, p53 expression was stably knocked down in MCF-7 cells using p53-shRNA (Santa Cruz Biotechnology). These clones (2 $\mu \mathrm{g}$ each/million cells) were introduced into MCF-7 cells using Lipofectamine 2000 (Invitrogen). Stably expressing clones were isolated by limiting dilution and selection with G418 sulphate (Cellgro) at a concentration of $400 \mu \mathrm{g} / \mathrm{ml}$, and cells surviving this treatment were cloned and screened by western blot analysis with the specific antibody. MCF-7 cells were transfected with 300 pmol of p38-MAPK-/Bax-/control-dssiRNA (Santa Cruz Biotechnology) and Lipofectamine 2000 separately for $12 \mathrm{~h}$. The protein levels of p53/p38MAPK/Bax were estimated by western blotting.

Western blot analysis. To obtain whole cell lysates, cells were homogenized in lysis buffer (20 mM HEPES, pH 7.5, $10 \mathrm{mM}$ $\mathrm{KCl}, 1.5 \mathrm{mM} \mathrm{MgCl} 2,1 \mathrm{mM} \mathrm{Na}-E D T A, 1 \mathrm{mM} \mathrm{Na-EGTA}$ and $1 \mathrm{mM}$ DTT) supplemented with protease and phosphatase inhibitor cocktails. Mitochondrial and cytosolic fractions were prepared (21). For direct western blot analysis, a total of $50 \mu \mathrm{g}$ of protein was resolved using SDS-PAGE and transferred to nitrocellulose membranes for western blotting using the relevant antibodies e.g., anti-caspase-6, anti-caspase-7, anti-caspase-9, anti-p53 (DO-1), anti-p-ser-46-p53, anti-Bax (N-20), anti-p38MAPK, anti-p-p38MAPK (pTGpY; Promega), anti-cytochrome- $c$ and anti-PUMA. The blots were developed with NBT/BCIP (1:1). Equivalent protein loading in cytosolic, nuclear and mitochondrial fractions was verified using anti- $\alpha$-actin/histone H1/MnSOD antibodies (Santa Cruz Biotechnology), respectively.
Statistical analysis. Values are shown as standard error of the mean, except when indicated otherwise. Data were analyzed, and appropriate significance $(\mathrm{P}<0.05)$ of the differences between mean values was determined by a Student's t-test.

\section{Results}

Thuja induces mammary epithelial carcinoma cell apoptosis. The effect of thuja on the viability of human breast cancer cell line MCF-7 and normal peripheral blood mononuclear cells (PBMCs) was examined at different potencies and placebos, i.e., 6C, 30C, 200C, where for each potency a differential dose of $0-30 \mu \mathrm{l} / \mathrm{ml}$ was applied (Fig. 1A). Total viable cells were scored by trypan blue dye exclusion assay. It was observed that among all the potencies of thuja, a 30C potency resulted in the most significant decrease $(\mathrm{P}<0.001)$ in cell viability as compared to its placebo treatment (Fig. 1A). Moreover, at a $20 \mu \mathrm{l} / \mathrm{ml}$ dose of 30C, the percent MCF-7 cell death reached a plateau (Fig. 1A) while under the same conditions the PBMC viability was found to be $>90 \%$ (Fig. 1A). These results indicated better efficacy of a $20 \mu \mathrm{l} / \mathrm{ml}$ dose of 30C thuja in MCF-7 cell killing with minimum toxicity leading us to perform all further experiments using this potency and dose of thuja. The time-dependent effect $(0-48 \mathrm{~h})$ of thuja at $30 \mathrm{C}(20 \mu \mathrm{l} / \mathrm{ml})$ in comparison to the placebo on MCF-7 and PBMCs was examined, and the percentage of cell death was assessed. Thuja at $30 \mathrm{C}$ at a concentration of $20 \mu \mathrm{l} / \mathrm{ml}$ exerted significant cell death in MCF-7 cells in a time-dependent manner. However, significant cell death in PBMCs was noted from $24 \mathrm{~h}$ onwards following thuja treatment (Fig. 1B).

To confirm the nature of cell death as apoptosis, Annexin V-PE/7AAD binding assay was utilized. Our flow cytometric data demonstrated that, in comparison to placebotreated MCF-7 cells, thuja-treated unfixed MCF-7 cells showed Annexin V-PE-binding with minimum 7AAD binding (Fig. 1C) indicating that the mode of cell death was apoptosis but not necrosis. These findings were confirmed by the presence of nuclear fragmentation as evidenced by DAPI-stained fluorescent images of the thuja-treated MCF-7 cells (Fig. 1D). Collectivelly, these data revealed that thuja at 30C asserts an apoptogenic effect on mammary epithelial cancer MCF-7 cells.

Thuja-induced apoptosis is favored in functional p53-expressing cells. Since tumor-suppressor protein p53 plays an important role in the canonical apoptotic pathway, we explored the changes in the protein profile of p53 after thuja administration in wild-type p53-expressing MCF-7 cells. Our results depicted a significant increase in the levels of p53 in MCF-7 cells after thuja treatment (Fig. 2A). To confirm whether or not thuja-induced cancer cell apoptosis is p53-dependent, the percentage of apoptosis as detected by Annexin binding was assessed in wild-type p53-expressing MCF-7 cells, p53-mutated MDA-MB-231 cells and p53-shRNA-transfected MCF-7 cells following thuja treatment (Fig. 2B). Notably, thuja at $30 \mathrm{C}$ at a $20 \mu \mathrm{l} / \mathrm{ml}$ dose significantly $(\mathrm{P}<0.001)$ induced apoptosis in the wild-type p53-expressing MCF-7 cells. The apoptogenic insult asserted by thuja was $\sim 38 \%$ as compared to the placebo effect which was only $10 \%$, while p53-mutated MDA-MB-231 and p53-knockdown MCF-7 cells were resistant to the thuja-induced insult (Fig. 2B). To understand the 
A
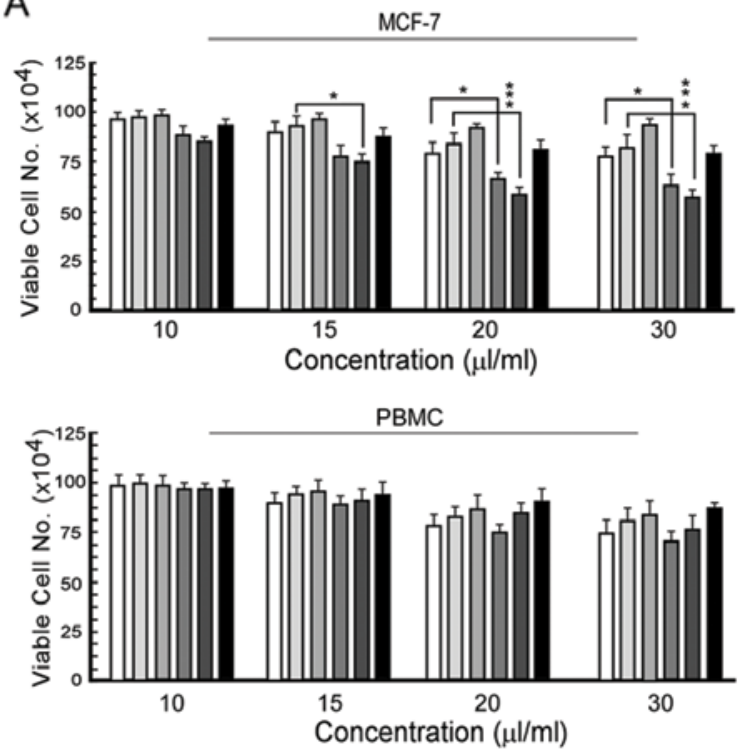

C

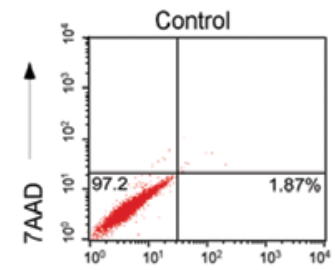

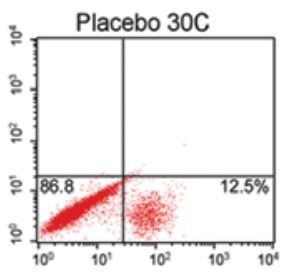

Annexin-V-PE $\longrightarrow$
B

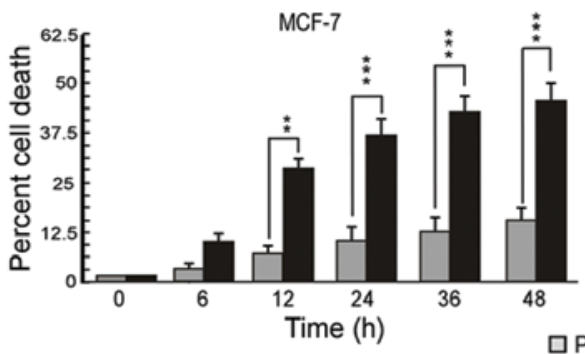

Placebo $30 \mathrm{C}$ $\square$ Placebo $200 \mathrm{C}$ $\square$ Thuja 6C $\square$ Thuja 30C - Thuja $200 \mathrm{C}$

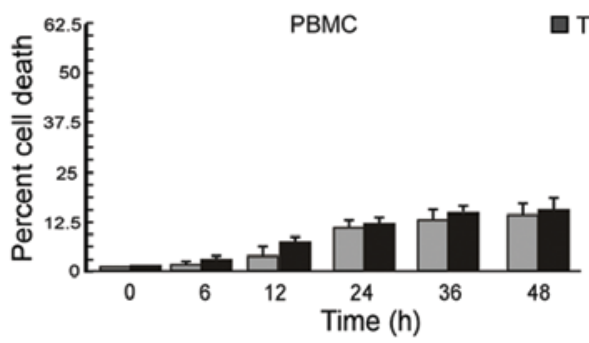

D

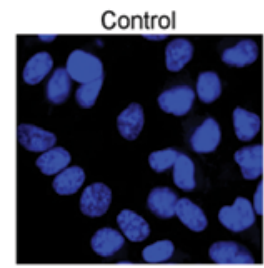

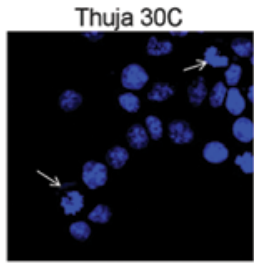

DAPI

Figure 1. Thuja induces apoptosis in breast cancer cells. (A) The number of viable MCF-7 cells (upper panel) and PBMCs (lower panel) following exposure to different potencies $(6 \mathrm{C}, 30 \mathrm{C}$ and $200 \mathrm{C})$ of placebo and thuja at different concentrations $(10,15,20$ and $30 \mu \mathrm{l} / \mathrm{ml})$ was determined by trypan dye exclusion assay, and the data are represented graphically $\left({ }^{*} \mathrm{P}<0.05,{ }^{* * *} \mathrm{P}<0.001\right.$ when compared with the respective placebo-treated group). (B) Percentage of cell death in $\mathrm{MCF}-7$ cells (upper panel) and PBMCs (lower panel) was determined following exposure to placebo and thuja at $30 \mathrm{C}(20 \mu 1 / \mathrm{ml})$ for different time intervals $(0,6,12,24$, 36 and $48 \mathrm{~h}$ ) by trypan blue positivity, and the data are represented graphically $\left({ }^{* *} \mathrm{P}<0.01,{ }^{* * *} \mathrm{P}<0.001\right.$ when compared with the respective placebo-treated group) (C) MCF-7 cells treated with placebo and thuja at 30C $(20 \mu \mathrm{l} / \mathrm{ml})$ for $24 \mathrm{~h}$ were subjected to Annexin V-PE/7AAD staining, and Annexin V-PE/7AAD-positive MCF-7 cells (regarded as apoptotic cells) were analyzed by flow cytometry. (D) DAPI staining showed nuclear blebbing (arrows) and nuclear fragmentation in the MCF-7 cells treated with thuja at 30C $(20 \mu \mathrm{l} / \mathrm{ml})$ when visualized under a fluorescence microscope. Values are the mean \pm SEM of three independent experiments in each case or representative of typical experiment.

mechanism of thuja-induced apoptosis, the p53 cellular localization of p53 in MCF-7 cells following thuja administration was examined by confocal microscopy. Translocation of the p53 protein from the cytosol to the nucleus was noted in the thuja-exposed MCF-7 cells (Fig. 2C). It is known that p53, being a transcription factor, is activated when localized in the nucleus and transactivates its downstream target genes. Therefore, the time-dependent accumulation of p53 both in the nuclear and cytosolic fractions and the status of its transactivated gene products, i.e., Bax and PUMA, in thuja-treated and untreated MCF-7 cells were examined by western blot analysis. Our results revealed that, in comparison to the untreated and placebo-treated tumor cells, thuja-exposed cells showed increased nuclear p53 expression with concomitant increase in the levels of p53 transactivated gene products, Bax and PUMA, in a time-dependent manner from $4 \mathrm{~h}$ onwards following thuja administration as detected by western blot analysis (Fig. 2D and $\mathrm{E})$. These results indicated that $\mathrm{p} 53$ is imperative for thujainduced functional p53-expressing MCF-7 cell apoptosis.

Thuja provokes ROS-p53 crosstalk in mammary cancer cells. Since reactive oxygen species (ROS) have been implicated as potential modulators of p53-dependent apoptosis, we explored the role of ROS in thuja-induced p53-dependent MCF-7 cell apoptosis. Our results revealed that, in comparison to the untreated and placebo-treated MCF-7 cells, exposure to thuja caused a significant increase in the levels of intracellular ROS in these functional p53-expressing cells (Fig. 3A and B). Notably, thuja-treated p53-shRNA-transfected MCF-7 cells showed a much significant reduction in the ROS level as compared to the functional p53-expressing MCF-7 cells although complete abrogation of ROS was not observed (Fig. 3A). Efficiency of p53-shRNA transfection was confirmed by western blot analysis (Fig. 3A, western blot). These findings indicated that thuja-induced ROS production was significantly and predominantly p53-dependent. These data suggest that p53 might regulate the intracellular redox status in these cancer cells and induce apoptosis by an ROS-dependent pathway. In addition, these results also indicated the possibility of p53-independent ROS production in the thuja-treated MCF-7 cells.

To further validate the role of ROS in thuja-induced p53-dependent apoptosis, two approaches were employed. Firstly, MCF-7 cells were pretreated with a pharmacological inhibitor of ROS, i.e., N-acetyl-L-cysteine (NAC), before 
A

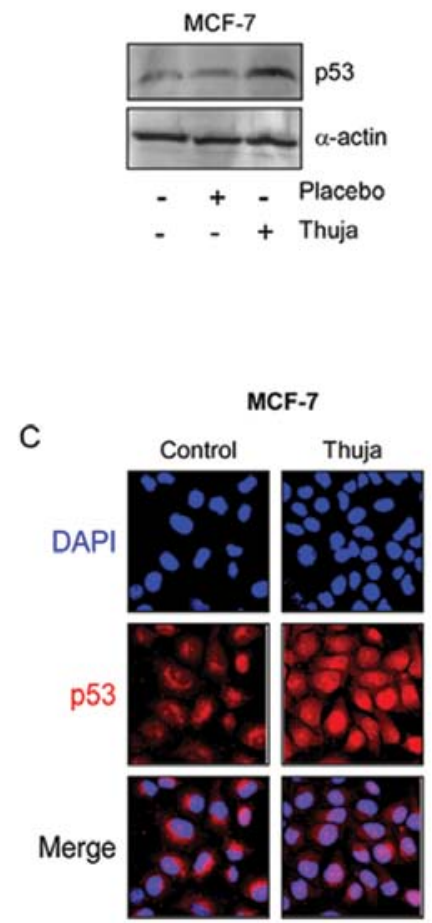

B

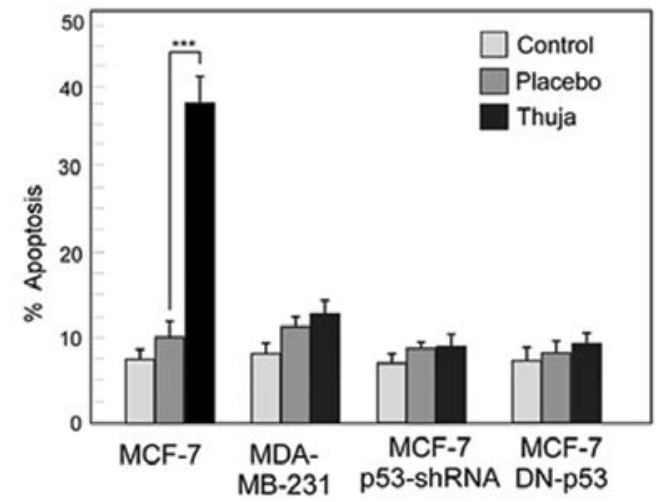

D

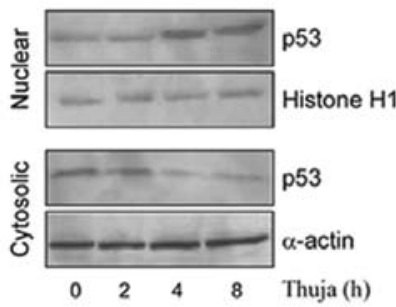

$E$

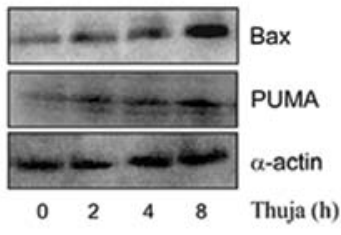

Figure 2. Apoptosis induced by thuja in breast cancer cells is p53-dependent. (A) Protein expression of p53 was determined by western blot analysis using anti-p53 (DO-1) antibodies in wild-type p53-expressing MCF-7 cell lysates, incubated with or without thuja at 30C (20 $\mu 1 / \mathrm{ml})$ or a placebo. (B) Wild-type p53-expressing (MCF-7), p53-mutated (MDA-MB-231), p53-shRNA-transfected MCF-7 and dominant-negative p53-transfected (MCF-7-DN-p53) cells were incubated in the presence or absence of thuja at $30 \mathrm{C}(20 \mu \mathrm{l} / \mathrm{ml})$ or a placebo for $24 \mathrm{~h}$, and the percentage of apoptosis by Annexin V-PE/7AAD positivity was determined by flow cytometry, and data are represented graphically. Values are the mean \pm SEM of three independent experiments in each case or representative of a typical experiment ${ }^{* * * *} \mathrm{P}<0.001$ when compared with the respective placebo-treated group). (C) p53 expression was visualized by confocal microscopy after fixation and permeabilization of control and thuja (30C; $20 \mu \mathrm{l} / \mathrm{ml})$-treated MCF7 cells using the anti-p53 antibody. (D) Expression of nuclear and cytosolic p53 was determined by western blot analysis in the MCF-7 cells treated with thuja at $30 \mathrm{C}(20 \mu \mathrm{l} / \mathrm{ml})$ for different time intervals $(0,2,4$ and $8 \mathrm{~h})$. (E) Expression levels of Bax and PUMA at the protein level were determined using cell lysates of MCF-7 cells treated with thuja at $30 \mathrm{C}(20 \mu \mathrm{l} / \mathrm{ml})$ for different incubation times $(0,2,4$ and $8 \mathrm{~h})$. $\alpha$-actin was used as an internal loading control.

thuja administration and secondly, $\mathrm{H}_{2} \mathrm{O}_{2}$, a pharmacological ROS inducer, was administered in the presence and absence of thuja. Thereafter, both the experimental sets were scored for the levels of intracellular ROS, levels of p53 in nuclear and cytosolic fractions and percent apoptosis. Notably, while NAC pretreatment resulted in loss of DCF-DA fluorescence (Fig. 3C), reduction in nuclear p53 levels (Fig. 3D) and significant decrease in percent apoptosis (Fig. 3E) in contrast to thuja administration alone, $\mathrm{H}_{2} \mathrm{O}_{2}$ treatment significantly upregulated intracellular ROS (Fig. 3C), increased nuclear p53 (Fig. 3D) and increased thuja-induced apoptosis (Fig. 3E). Since the silencing of p53 abrogates ROS production and inhibition of ROS decreases p53 expression, there is the inter-dependency and crosstalk between p53 and ROS in executing thuja-induced apoptosis.

Thuja-induced ROS activate p53 in a p38MAPK-dependent manner to generate a feedback loop. It is known that p53 is a redox-regulated transcription factor. Thus, to delineate the functional impact of thuja-induced ROS on p53 activation, several experiments were designed. Our earlier findings implicated the role of thuja-induced ROS in nuclear translocation of p53, a prerequisite for its transcriptional activation (Fig. 3D). It is known that to circumvent diverse activities in response to varied stress stimuli, p53 protein is under tight regulatory control of post-translational modifications where phosphorylation is one of the key events modulating p53 functions (22). Our search for the factor(s) responsible for functional activation of p53 revealed that, in response to thuja, p53 manifested phosphorylation at serine 46 residues (Fig. 4A). Based on previous research which found that p38MAPK regulates p53 function in response to ROS-induced DNA damage (23), we evaluated the role, if any, of p38MAPK in thuja-induced p53 activation. Our results indicated upregulation of the phosphorylated form of p38MAPK without intervention of the total p38MAPK status in MCF-7 cells following thuja treatment with simultaneous phosphorylation of p53 at Ser46 and an increase in p53 transactivated gene product, Bax, while the placebo failed to display any such effect (Fig. 4A).

Based on earlier observations which confirmed the critical role of ROS in manipulating the levels of nuclear p53, we attempted to clarify the mechanistic link between thujainduced ROS, p38MAPK and p53 phosphorylation. Thus, we analyzed the level of total p38MAPK, p-p38MAPK and p-Ser46-p53 in thuja-induced MCF-7 cells upon administration of either NAC or $\mathrm{H}_{2} \mathrm{O}_{2}$. As shown in Fig. 4A, NAC pretreatment abolished phosphorylation of p38MAPK without affecting total p38MAPK and simultaneously significantly 
A

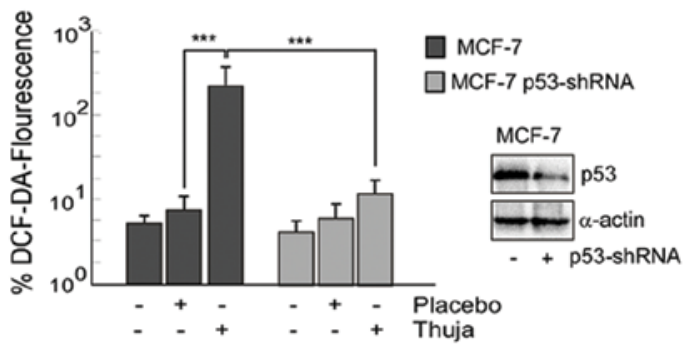

B

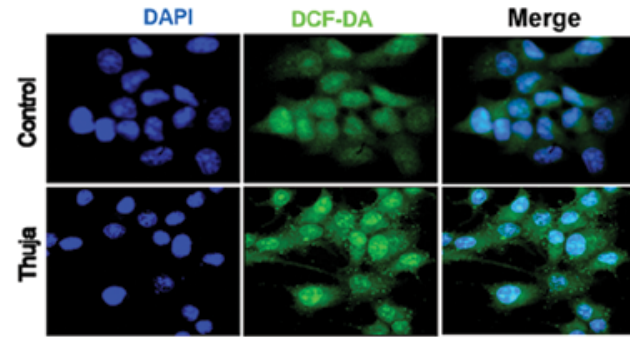

C

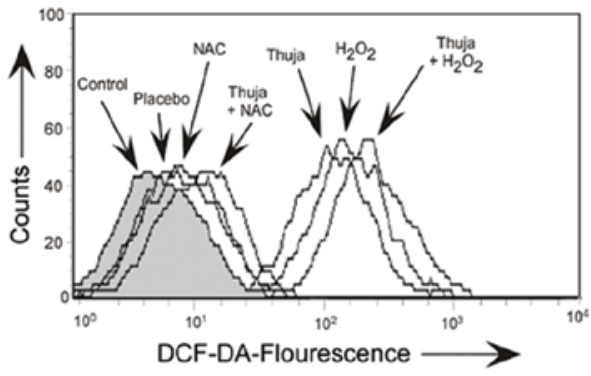

D

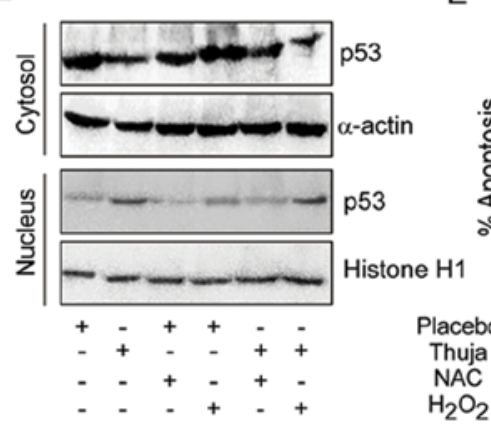

E

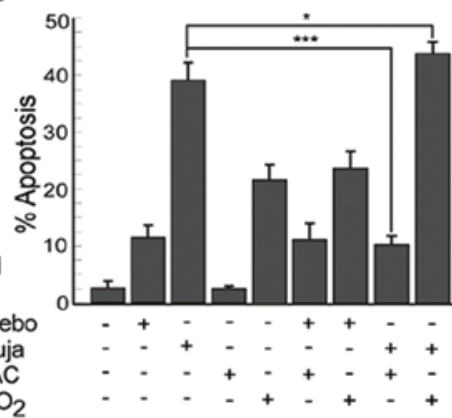

Figure 3. Generation of ROS in thuja-induced apoptosis of p53-expressing MCF-7 cells. (A) MCF-7 and p53-shRNA-transfected MCF-7 cells were incubated in the presence or absence of thuja at $30 \mathrm{C}(20 \mu \mathrm{l} / \mathrm{ml})$ or a placebo for $24 \mathrm{~h}$. The cells were assessed by flow cytometry for ROS generation, and data are expressed graphically $\left({ }^{* * *} \mathrm{P}<0.001\right.$ when compared with the placebo-treated group) showing the percentage of DCF-DA-fluorescence intensity. The efficiency of p53-shRNA transfection was also verified by western blot analysis. (B) ROS was visualized by confocal microscopy after fixation and permeabilization of the control and thuja $(30 \mathrm{C} ; 20 \mu \mathrm{l} / \mathrm{ml})$-treated MCF7 cells using DCF-DA-fluorescence dye. (C) Flow cytometric analysis of thuja (30C; $20 \mu \mathrm{l} / \mathrm{ml})$-induced ROS production with/without NAC, a pharmacological inhibitor of ROS and with/without $\mathrm{H}_{2} \mathrm{O}_{2}$, an enhancer of ROS generation represented by histogram overlay. (D) Nuclear and cytosolic expression of p53 was determined by western blot analysis in NAC or $\mathrm{H}_{2} \mathrm{O}_{2}$ pretreated MCF-7 cells in the presence or absence of thuja at $30 \mathrm{C}(20 \mu \mathrm{l} / \mathrm{ml})$. (E) In a parallel experiment, the percentage of apoptosis was determined by Annexin V-PE/7AAD staining, and data are represented graphically $\left({ }^{*} \mathrm{P}<0.05,{ }^{* * *} \mathrm{P}<0.001\right.$ when compared with the thuja-treated group).

decreased the p-Ser46-p53 level. Reduction in intracellular ROS levels in NAC-treated cells further confirmed the inhibitor efficiency (Fig. 3C). In contrast, treatment with $\mathrm{H}_{2} \mathrm{O}_{2}$ resulted in an increase in p-p38MAPK and phosphorylated-p53 levels. An increase in DCF-DA fluorescence in the $\mathrm{H}_{2} \mathrm{O}_{2}$-treated cells confirmed an increase in intracellular ROS levels (Fig. 3C). All of these results together underscore the role of ROS in sustaining the activity of p38MAPK and p53.

p38MAPK-dependent p53 transactivation causes thuja induced apoptosis. To ascertain the contribution of p38MAPK in thuja-mediated apoptosis through post-translational modification of p53, transiently silenced p38MAPK MCF-7 cells were used and analyzed for the status of p-Ser46-p53 and Bax. The percentage of apoptosis was also determined in these engineered as well as control MCF-7 cells with and without thuja administration. The silencing of p38MAPK downregulated the p-p38MAPK level in the transfectants thereby confirming the transfection efficiency (Fig. 4B, western blot) and this decrease in p-p38MAPK significantly decreased thujainduced apoptosis (Fig. 4B). It was observed that in contrast to the thuja-treated wild-type MCF-7 cells, p38MAPK-silenced MCF-7 cells exhibited decreased p-Ser46-p53 (Fig. 4C). Consequently, our results confirmed that p38MAPK plays a crucial role in functionally triggering p53 to execute its transcriptional functions and finally to execute apoptosis. To further validate the sequence of events, p38MAPK-silenced MCF-7 cells with and without thuja administration were analyzed for intracellular ROS levels employing DCF-DA staining. Notably, the silencing of p38MAPK in MCF-7 cells resulted in a significant decrease in DCF-DA fluorescence signifying the role of p38MAPK in ROS production following thuja administration (Fig. 4E). Additionally, similar to p53-knockout cells, p38MAPK-silenced MCF-7 cell also could not neutralize the ROS level completely while inhibiting ROS downregulated p-p38MAPK.

Thuja-induced ROS-p38MAPK-p53 feedback loop is maintained through p53 transactivation. Results of the above experiments indicated the potential role of ROS in p53 nuclear translocation. As shown in Fig. 2E, an increase in Bax and PUMA protein levels in MCF-7 cells following thuja exposure confirmed that nuclear p53 is transcriptionally active. Next, to ensure the involvement of p53-transactivated Bax in thuja-induced apoptosis, MCF-7 cells were pretreated with pifithrin- $\alpha$ (24) before evaluating thuja-induced apoptosis. The results demonstrated that blocking p53-mediated transactivation inhibited thuja-induced cancer cell death, thereby confirming the involvement of the p53-mediated transactivation pathway in thuja-induced apoptosis (Fig. 4D). While examining the p53 transactivated product, it was observed that pifithrin- $\alpha$-exposed cells, although exhibiting an increased p53 level, however, showed a decrease in the expression levels of Bax and PUMA following thuja administration (Fig. 4F).

In a parallel experiment, the role of ROS on the p53 transactivated gene products, ie., Bax, was analyzed in NAC- or $\mathrm{H}_{2} \mathrm{O}_{2}$-pretreated thuja-exposed MCF-7 cells. It was observed that while the quenching of ROS by NAC diminished the 
A

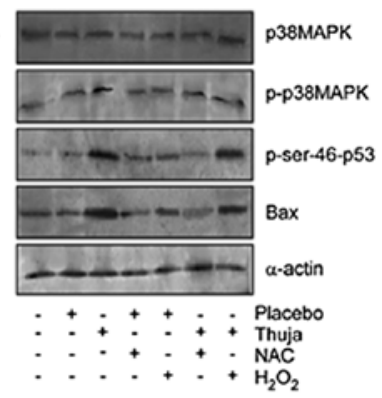

E

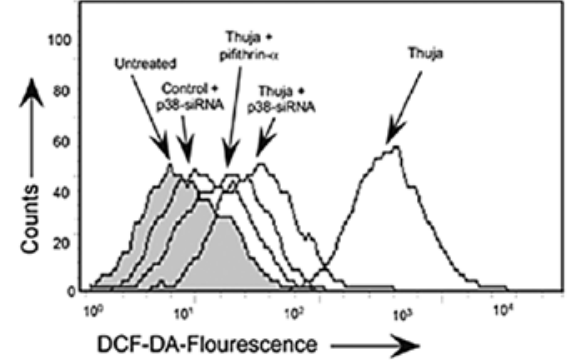

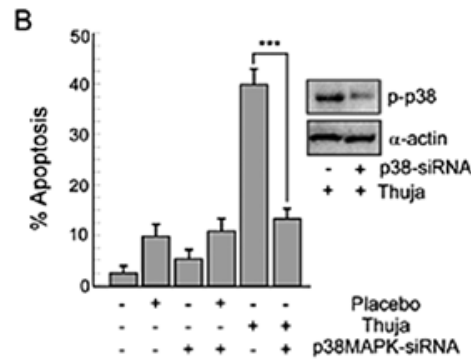

$\mathrm{F}$

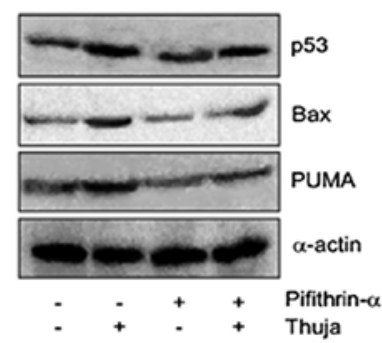

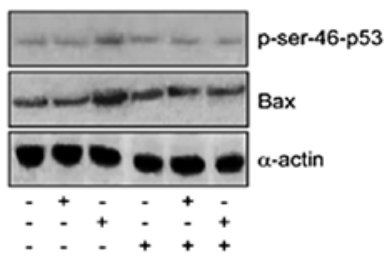

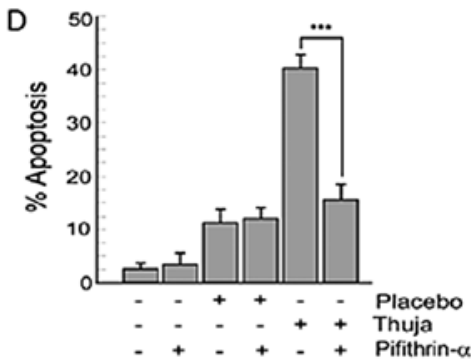

G

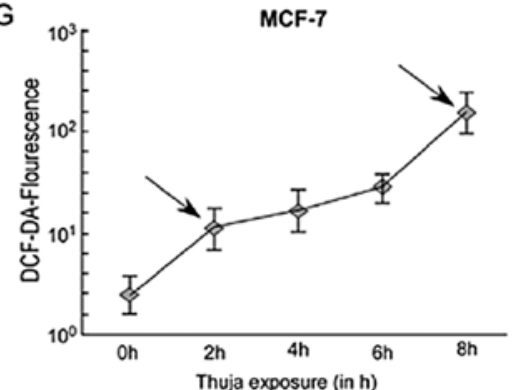

Figure 4. Thuja-induced ROS generation in MCF-7 cells is through activation of the p38MAPK pathway. (A) MCF-7 cells were treated with thuja at 30C $\left(20 \mu \mathrm{l} / \mathrm{ml}\right.$ for $24 \mathrm{~h}$ ) in the presence or absence of NAC or $\mathrm{H}_{2} \mathrm{O}_{2}$ and the protein expression profile of p38MAPK, p-p38MAPK, p-Ser-46-p53 and Bax was determined by western blot analysis. (B) MCF-7 cells transfected with p38MAPK-siRNA were subjected to thuja $(20 \mu 1 / \mathrm{ml}$ for $24 \mathrm{~h})$ treatment and were scored for the percentage of apoptosis by Annexin V-PE/7AAD positivity, and data are represented graphically ${ }^{* * *} \mathrm{P}<0.001$ when compared with the thuja-treated group). The efficiency of p38MAPK-siRNA transfection was also verified by western blot analysis (right panel). (C) MCF-7 cells transfected with p38MAPKsiRNA followed by thuja $(20 \mu \mathrm{l} / \mathrm{ml})$ exposure were analyzed by western blot analysis to determine the protein levels of p-Ser-46-p53 and Bax. (D) MCF-7 cells pre-exposed to pifithrin- $\alpha$ were treated with thuja at $30 \mathrm{C}(20 \mu \mathrm{l} / \mathrm{ml}$ for $24 \mathrm{~h})$, and the percentage of apoptosis was scored using flow cytometry by Annexin V-PE/7AAD positivity, and data are represented graphically $\left({ }^{* * *} \mathrm{P}<0.001\right.$ compared to thuja treatment). (E) ROS production was determined by flow cytometry by measuring DCF-DA-fluorescence in p38MAPK-siRNA transfected and pifithrin- $\alpha$ (a p53 transcriptional blocker)-treated MCF-7 cells in the presence or absence of thuja at $30 \mathrm{C}(20 \mu \mathrm{l} / \mathrm{ml})$. (F) In the same set of experiments, the protein expression of p53, Bax and PUMA was evaluated by western blot analysis. $\alpha$-actin was used as an internal loading control. (G) ROS production at different time points $(2,4,6$ and $8 \mathrm{~h})$ in the MCF- 7 cells treated with thuja at $30 \mathrm{C}(20 \mu \mathrm{l} / \mathrm{ml})$ was determined using flow cytometry by measuring DCF-DA-fluorescence, and data are represented in a line diagram; arrows indicate the biphasic ROS generation.

levels of $\mathrm{Bax}, \mathrm{H}_{2} \mathrm{O}_{2}$ exposure upregulated this p53-transactivated product (Fig. 4A). Additionally, to investigate the contribution of $\mathrm{p} 53$ transactivation in thuja-mediated ROS generation and subsequent apoptosis, the transactivation of p53 was blocked by pre-exposing MCF-7 cells to pifithrin- $\alpha$ and then intracellular ROS levels and apoptosis were assessed. Abrogating p53 transcriptional functions in MCF-7 cells resulted in significant downregulation of ROS production even upon thuja administration (Fig. 4E). Remarkably, it was found that these pifithrin- $\alpha$-treated cells, similar to p53-knockout or p38MAPK-silenced MCF-7 cells, also failed to neutralize the intracellular ROS level completely, thereby pointing towards the possibility of p38MAPK-p53 crosstalk independent of ROS generation. These apparently 'contradictory' findings point towards the presence of an ROS-p-p38MAPK-p53 feedback loop that executes apoptosis in thuja-treated MCF-7 cells.

Thuja-induced bi-phasic ROS generation via p53-transactivated Bax maintains a feedback loop. The obtained results portrayed the potential role of ROS in thuja-induced apoptosis. It was also revealed that the ROS-induced apoptosis was not only p53- and p38MAPK-dependent but could also act independently. In these circumstances the possibility for the production of early ROS was assumed which may be produced before p38MAPK and p53 activation. The above assumption was confirmed when the time frame of ROS production was determined. Our effort to unveil this 'mystery' divulged a bi-phasic increase in ROS, with the first peak being at $2 \mathrm{~h}$ (Fig. 4G), even before p53 nuclear translocation that had an onset from $4 \mathrm{~h}$ following thuja exposure (Fig. 2D). This was followed by a second higher peak of ROS production at $8 \mathrm{~h}$ following thuja exposure (Fig. 4G) the timing of which matched with the p53 transactivated Bax expression following thuja exposure (Fig. 2E). Our earlier results revealed that the knockout of p53 (Fig. 3A) or the blocking of p53 transcriptional activity (Fig. 4E) resulted in a significant decrease in ROS levels. Therefore it was hypothesized that the second peak of ROS was induced by activated p53. To further confirm this crosstalk, Bax-deprived MCF-7 cells with or without thuja administration were analyzed for intracellular ROS levels. These findings confirmed the role of thuja in the generation of p53-independent early phase ROS in p53 activation via p38MAPK that finally potentiated p53 nuclear translocation and Bax transactivation which directed the second peak of ROS. Additionally, these findings allowed us to hypothesize that the p53-dependent second phase of ROS is instrumental in maintaining p53 activation through the ROS-p38MAPK-p53 feedback loop while executing thuja-induced apoptosis. Subsequent experiments were designed to identify the source of ROS generation after $8 \mathrm{~h}$ of thuja exposure in MCF-7 cells. Notably, blocking of mitochondrial disruption abrogated an increase in ROS levels at $8 \mathrm{~h}$ (Fig. 5A) thereby indicating the contribution of mitochondrial membrane disruption in thujainduced ROS generation at a late time period. 
A

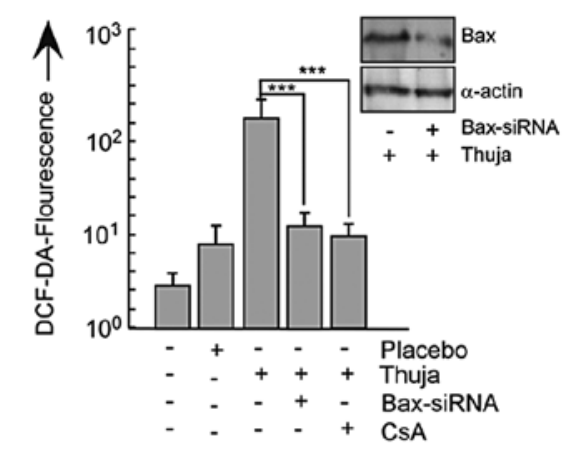

D

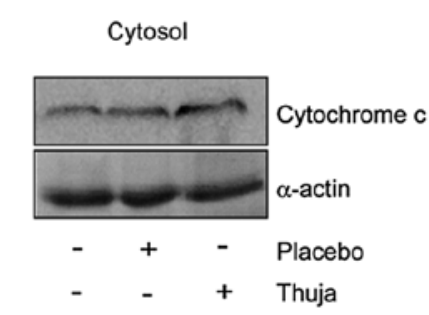

B

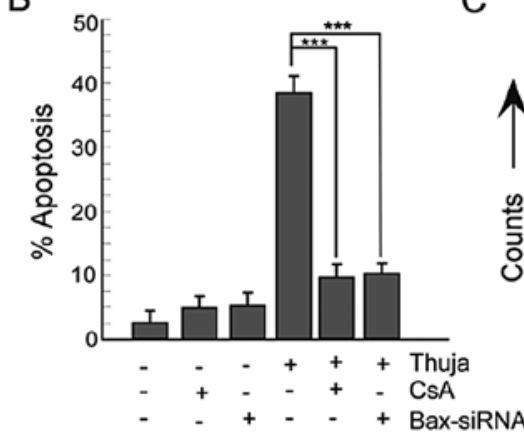

E

C

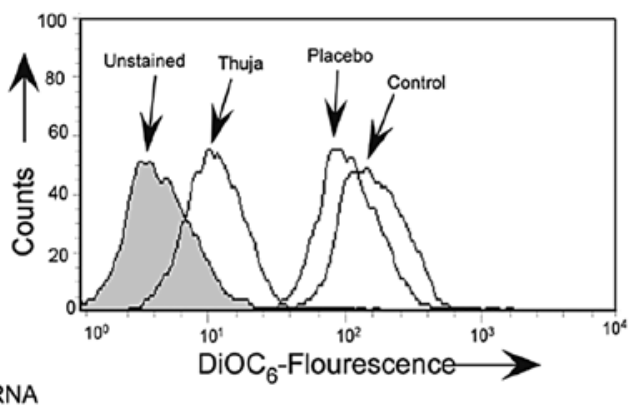

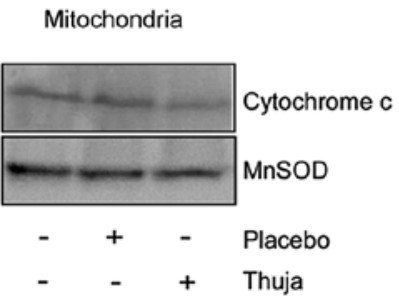

Figure 5. Thuja induces the Bax-dependent mitochondrial death cascade in MCF-7 cells. (A) Untreated cells, Bax-siRNA-transfected cells and cyclosporine A (CsA; a mitochondrial pore blocker)-treated MCF-7 cells were incubated with or without thuja for $8 \mathrm{~h}$ and were evaluated by flow cytometry for mean DCF-DA-fluorescence as evidence for ROS generation, and data are represented in a bar diagram ( ${ }^{* * *} \mathrm{P}<0.001$ when compared with the thuja-treated group). The efficiency of the transfections was assessed by evaluating the expression of Bax by western blotting (right panel). (B) In the same set of experiments, the cells were assessed using flow cytometry for the percentage of apoptosis by Annexin V-PE/7AAD positivity, and data are represented graphically $\left({ }^{* * *} \mathrm{P}<0.001\right.$ when compared with the thuja-treated group). (C) MCF-7 cells were incubated with or without thuja at $30 \mathrm{C}$ (20 $\mu \mathrm{l} / \mathrm{ml})$ or a placebo for $8 \mathrm{~h}$ and were monitored for mitochondrial transmembrane potential (MTP) loss by DiOC $_{6}$ fluorescence using flow cytometry. (D) Expression of cytochrome $c$ in the mitochondria and in the cytosol following placebo and thuja treatment in MCF-7 cells was determined by western blot analysis. (E) Untreated or CsA-pretreated MCF-7 cells were incubated with or without thuja at $30 \mathrm{C}(20 \mu \mathrm{l} / \mathrm{ml})$, and the variation in the expression profiles of active caspase-9, -7 and -6 were determined by western blot analysis. $\alpha$-actin was used as an internal loading control.

ROS-p53 feedback loop prepares the mitochondrial death cascade in thuja-treated MCF-7 cells. An increase in Bax in apoptogenic cells tempted us to explore the involvement of Bax in the mitochondrial cascade-mediated apoptosis. For this two approaches were employed. Firstly, MCF-7 cells were transfected with Bax-siRNA and secondly, MCF-7 cells were pretreated with cyclosporine A (CsA), the mitochondrial pore formation blocker, before thuja exposure. The silencing of Bax or the inhibition of mitochondrial pore formation resisted the thuja-induced ROS production (Fig. 5A) and significantly decreased the percentage of apoptosis of MCF-7 cells (Fig. 5B). Gene manipulation or pharmacological inhibition of p53-transactivation product Bax failed to neutralize ROS completely reflecting the results of p53-knockout or the p38MAPK-silencing. In the downstream of Bax, the involvement of mitochondria was further confirmed by $\mathrm{DiOC}_{6}$-florescent dye that demonstrated significant mitochondrial transmembrane potential (MTP) loss in thuja-exposed MCF-7 cells as compared to the control and placebo-treated MCF-7 cells (Fig. 5C). These findings confirmed the role of mitochondria in executing the thuja-induced p53-transactivated Bax-mediated apoptotic cascade. Detail inspection determined that unlike the untreated and placebo-treated cells, the thuja-treated MCF-7 cells showed a significant decrease in cytochrome $c$ level in mitochondria with a simultaneous increase in the cytosol (Fig. 5D).
This ROS-p53 feedback loop activates the mitochondrial death signal through cytochrome $c$ release finally culminating in apoptosis. Further search for the downstream mechanism revealed that thuja influenced the execution phase of apoptosis through activation of the initiator caspase- 9 followed by effector caspase-6 and -7 (Fig. 5E) in these MCF-7 cells that lack functional caspase-3. Blocking mitochondrial pore formation downregulated these caspases and thereby implicated mitochondrial membrane disruption in thuja-induced caspase activation and apoptosis (Fig. 5E). Mitochondrial membrane disruption was downstream of Bax transactivation by p53. These results further signify the existence of a feedback loop in thuja-treated MCF-7 cells in which ROS act both as an initiator of p53 activation as well as plays a significant role in maintaining p53 in an activated state via p38MAPK.

\section{Discussion}

Thuja, a bioactive derivative of Thuja occidentalis, has been widely accredited for its antitumorigenic potential $(25,26)$. Although reports have verified the anticancer effect of this remedy (8-10), detailed reports elucidating the molecular mechanisms underlying the anticancer effect of thuja are needed. The present study demonstrated that the antitumorigenic effect of thuja on breast cancer cells was not a 'placebo effect' as the placebo (potentized hydro-alcoholic solution)-treated cells 


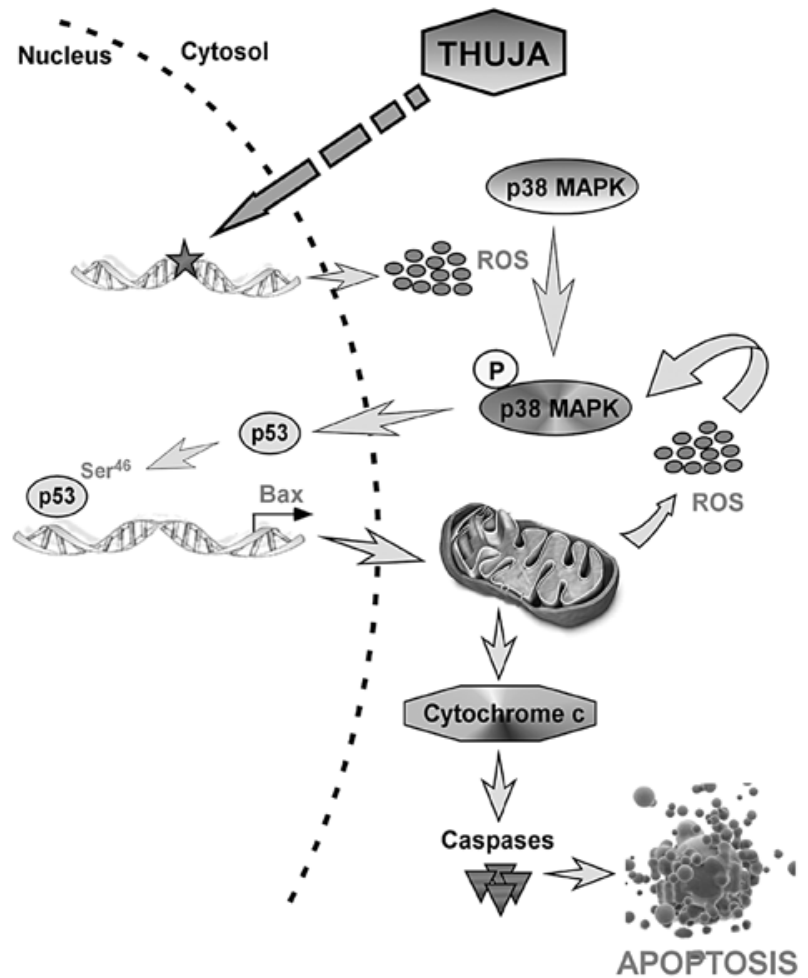

Figure 6. Proposed mechanism of action of the thuja-induced apoptosis in mammary epithelial carcinoma MCF-7 cells by an ROS-p53 feedback loop.

failed to induce significant cell death when compared to the control cells. The present study further revealed that thuja asserted its effects by re-orienting the molecular choreography of cancer cells. Importantly, the preferential induction of the cytotoxic effects in breast cancer cells, as compared to normal cells, suggests a safe and non-toxic therapeutic opportunity.

It was shown that thuja is a potent inducer of apoptosis in mammary epithelial carcinoma cells, with a more pronounced effect in wild-type p53-expressing cells than in functional p53-deficient cells; the contribution of p53-dependent signaling being the underlying reason. However, two previous independent reports from Thangapazham et al (27) and MacLaughlin et al (28) failed to confirm the inhibitory effects of thuja in breast cancer cells and prostate cancer cells in vitro, respectively. These apparently paradoxical results were obtained since the studies tested the efficacy of Thuja occidentalis on functional p53-deficient breast cancer MDA-MB-231 cells and prostate cancer DU145 cells, as well as on p53-null prostate cancer PC 3 cells. Conversely, thuja efficiently triggered the apoptotic cascade in the human melanoma A375 cell line (9) and in lymphoma cells (29), which express wild-type p53. These findings corroborate the dependence of thuja-induced apoptosis on the p53 status. Our study further points toward an increase in expression as well as nuclear translocation of wildtype p53 in thuja-exposed breast cancer cells. Moreover, the differential susceptibility of these cell types also indicates that the cytotoxic activities of thuja are dependent on the genetic background of the cancer cells.

In the present study, it was found that thuja-induced p53-dependent apoptosis in breast cancer cells was mediated by oxidative stress. This is in accordance with recent reports where induction of oxidative stress in response to anticancer drugs derived from natural products has been implicated in the activation of redox-regulated transcription factor p53-dependent apoptosis in cervix carcinoma cells (30). Moreover, in this study, ROS generation followed a bi-phasic pattern showing a peak at an early time-point and another higher one at a late time-point. Although the silencing of p53 reduced ROS production but failed to block it completely, early ROS were generated even before p53 nuclear translocation. Thus, it was hypothesized that ROS, generated at an early time frame, were p53-independent and might be generated due to initial DNA breakdown induced by thuja, similar to other DNA-damaging anticancer agents, e.g., actinomycin D, cycloheximide and vincristine, to activate p53 (31). This hypothesis was validated by the experimental data which revealed that attenuated ROS production by $\mathrm{N}$-acetyl cysteine (NAC) inhibited p53 expression as well as retarded its nuclear translocation in breast cancer cells. In contrast, increasing ROS by $\mathrm{H}_{2} \mathrm{O}_{2}$ aided in $\mathrm{p} 53$ activation and translocation. Notably, in these cells activated p53 upregulated ROS in a feedback loop to trigger apoptosis. The present study indicates the pivotal role of thuja in triggering p53-dependent apoptosis through a bi-phasic increase in ROS production.

Previous reports have shown that ROS direct p53-mediated apoptosis through the aid of mitogen-activated protein kinases (MAPKs) (32) that are instrumental in p53 phosphorylation and required for its activation (33). In fact, phosphorylation of p53 at Ser15 and Ser20 due to DNA damage, at Ser15 and Ser37 by ATM and ATR and at Ser20 by Chk 2 and Chk1, enhances its stability and nuclear activity (34). Furthermore, it is proposed that p38 stress kinase also plays a prominent role in genotoxic stress-induced activation of p53 through phosphorylation at Ser46 (33). In line with the general understanding of ROS and p53 regulation, it was reported that thuja-induced ROS generation triggered $\mathrm{p} 38 \mathrm{MAPK}-$ mediated phosphorylation of p53 at Ser46 residue. It is well appreciated that phosphorylation of p53 at the Ser46 residue regulates the transcriptional activation of the apoptosis-inducing gene (35). The attenuation of the apoptotic extent in p53-silenced or pifithrin- $\alpha$ (a transcriptional inhibitor of p53)-treated MCF-7 cells confirmed the transactivational role of p53 in thuja-induced apoptosis. Moreover, the silencing of Bax, a p53 transactivating product, reduced ROS generation as well as apoptosis thereby authenticating that $\mathrm{p} 53$-mediated Bax transactivation was required for ROS generation and apoptosis in thuja-treated MCF-7 cells. It is also anticipated that, as the half-life of p53 protein is very short (36), thuja-initiated cascade of pro-apoptotic events resulting in the upsurge of mitochondrial ROS may escalate DNA damage to maintain the p53 level in these cells. Involvement of the mitochondria was further endorsed when ROS generation and the percentage of apoptosis was reversed by $\mathrm{CsA}$, a mitochondrial pore formation blocker.

Collectively, these results point towards a ROS-p53 feedback loop in which, at an early phase, thuja generates ROS to activate $\mathrm{p} 53$ via $\mathrm{p} 38 \mathrm{MAPK}$ that in turn transactivates Bax to initiate mitochondrial changes including the second phase of ROS generation. This second phase of ROS not only helps maintain p53 through p38MAPK activation but also magnifies the thuja signal to finally activate the caspase cascade (Fig. 6). Such a self-regulatory feedback partnership, in fact, amplifies and accelerates the death of breast cancer cells by thuja. 
In conclusion, the present study demonstrated a dual role of ROS, specifically, as an upstream signal that triggers p53 activation and as a downstream effector to amplify the ROS-p53 feedback loop to sustain p53 function in inducing apoptosis, in thuja-mediated breast cancer cell apoptosis. Overall these findings provide evidence for a molecular signature of the thuja effects in human mammary epithelial carcinoma cells and lay the foundation for the biological impact of the nontoxic phytochemical thuja in clinical trials.

\section{Acknowledgements}

The authors are thankful to Mr. Uttam Ghosh and Mr. Ranjan Dutta for their technical help. The present study was supported by grants from the Central Council for Research in Homeopathy (CCRH), Government of India.

\section{References}

1. Hanf $\mathrm{V}$ and Gonder U: Nutrition and primary prevention of breast cancer: foods, nutrients and breast cancer risk. Eur J Obstet Gynecol Reprod Biol 123: 139-149, 2005.

2. Cassileth BR and Vickers AJ: Complementary and alternative therapies. Urol Clin North Am 30: 369-376, 2003.

3. Flinn JE: Bromium in acute lymphatic leukemia. J Am Inst Homeopath 58: 213-214, 1965.

4. Gruchmann W: Arsenic: destroyer and healer; a contribution to the management of carcinoma. Hippokrates 27: 444-445, 1956 (In German)

5. Pathak S, Multani AS, Banerji P and Banerji P: Ruta 6 selectively induces cell death in brain cancer cells but proliferation in normal peripheral blood lymphocytes: a novel treatment for human brain cancer. Int J Oncol 23: 975-982, 2003.

6. Pathak S, Kumar Das J, Jyoti Biswas S and Khuda-Bukhsh AR: Protective potentials of a potentized homeopathic drug, Lycopodium-30, in ameliorating azo dye induced hepatocarcinogenesis in mice. Mol Cell Biochem 285: 121-131, 2006.

7. Frenkel M, Mishra BM, Sen S, Yang P, Pawlus A, Vence L, Leblanc A, Cohen L, Banerji P and Banerji P: Cytotoxic effects of ultra-diluted remedies on breast cancer cells. Int J Oncol 36 395-403, 2010

8. Ojeswi BK, Khoobchandani M, Hazra DK and Srivastava MM: Protective effect of Thuja occidentalis against DMBA-induced breast cancer with reference to oxidative stress. Hum Exp Toxicol 29: 369-375, 2010

9. Biswas R, Mandal SK, Dutta S, Bhattacharyya SS, Boujedaini N and Khuda-Bukhsh AR: Thujone-rich fraction of Thuja occidentalis demonstrates major anti-cancer potentials: evidences from in vitro studies on A375 cells. Evid Based Complement Alternat Med 2011: 568148, 2011.

10. Naser B, Bodinet $\mathrm{C}$, Tegtmeier $\mathrm{M}$ and Lindequist U: Thuja occidentalis (Arbor vitae): a review of its pharmaceutical, pharmacological and clinical properties. Evid Based Complement Alternat Med 2: 69-78, 2005

11. Sunila ES and Kuttan G: Protective effect of Thuja occidentalis against radiation-induced toxicity in mice. Integr Cancer Ther 4 322-328, 2005

12. Sunila ES and Kuttan G: A preliminary study on antimetastatic activity of Thuja occidentalis L. in mice model. Immunopharmacol Immunotoxicol 28: 269-280, 2006.

13. Dubey SK and Batra A: Hepatoprotective activity from ethanol fraction of Thuja occidentalis Linn. Asian J Res Chem 1: 32-35, 2008.

14. Dubey SK and Batra A: Antioxidant activity of Thuja occidentalis Linn. Asian J Pharm Clin Res 2: 73-76, 2009.

15. Efeyan A and Serrano M: p53: guardian of the genome and policeman of the oncogenes. Cell Cycle 6: 1006-1010, 2007.

16. Liu B, Chen Y and St Clair DK: ROS and p53: a versatile partnership. Free Radic Biol Med 44: 1529-1535, 2008.

17. Pervaiz S and Clement MV: Tumor intracellular redox status and drug resistance - serendipity or a causal relationship? Curr Pharm Des 10: 1969-1977, 2004.
18. Mandal D, Lahiry L, Bhattacharyya A, Chattopadhyay S, Siddiqi M, Sa G and Das T: Black tea protects thymocytes in tumor-bearing animals by differential regulation of intracellular ROS in tumor cells and thymocytes. J Environ Pathol Toxicol Oncol 24: 91-104, 2005

19. Adhikary A, Mohanty S, Lahiry L, Hossain DM, Chakraborty S and Das T: Theaflavins retard human breast cancer cell migration by inhibiting NF- $\kappa \mathrm{B}$ via p53-ROS cross-talk. FEBS Lett 584 : 7-14, 2010.

20. Mazumdar M, Adhikary A, Chakraborty S, Mukherjee S, Manna A, Saha S, Mohanty S, Dutta A, Bhattacharjee P, Ray P, Chattopadhyay S, Banerjee S, Chakraborty J, Ray AK, Sa G and Das T: Targeting RET to induce medullary thyroid cancer cell apoptosis: an antagonistic interplay between PI3K/Akt and p38MAPK/caspase-8 pathways. Apoptosis 18: 589-604, 2013

21. Lahiry L, Saha B, Chakraborty J, Bhattacharyya S, Chattopadhyay S, Banerjee S, Choudhuri T, Mandal D, Bhattacharyya A, Sa G and Das T: Contribution of p53-mediated Bax transactivation in theaflavin-induced mammary epithelial carcinoma cell apoptosis. Apoptosis 13: 771-781, 2008.

22. Saito S, Yamaguchi H, Higashimoto $\mathrm{Y}$, Chao $\mathrm{C}, \mathrm{Xu} \mathrm{Y}$, Fornace AJ Jr, Appella E and Anderson CW: Phosphorylation site interdependence of human p53 post-translational modifications in response to stress. J Biol Chem 278: 37536-37544, 2003.

23. Freund A, Patil CK and Campisi J: p38MAPK is a novel DNA damage response-independent regulator of the senescenceassociated secretory phenotype. EMBO J 30: 1536-1548, 2011.

24. Murphy PJ, Galigniana MD, Morishima Y, Harrell JM, Kwok RP, Ljungman $M$ and Pratt WB: Pifithrin- $\alpha$ inhibits p53 signaling after interaction of the tumor suppressor protein with hsp90 and its nuclear translocation. J Biol Chem 279: 30195-30201, 2004.

25. Chang LC, Song LL, Park EJ, Luyengi L, Lee KJ, Farnsworth NR, Pezzuto JM and Kinghorn AD: Bioactive constituents of Thuja occidentalis. J Nat Prod 63: 1235-1238, 2000.

26. British Herbal Pharmacopoeia. Thuja, British HerbalMedicine Association, West Yorks, UK, 1983.

27. Thangapazham RL, Gaddipati JP, Rajeshkumar NV, Sharma A, Singh AK, Ives JA, Maheshwari RK and Jonas WB: Homeopathic medicines do not alter growth and gene expression in prostate and breast cancer cells in vitro. Integr Cancer Ther 5: 356-361, 2006.

28. MacLaughlin BW, Gutsmuths B, Pretner E, Jonas WB, Ives J, Kulawardane DV and Amri H: Effects of homeopathic preparations on human prostate cancer growth in cellular and animal models. Integr Cancer Ther 5: 362-372, 2006.

29. Preethi K, Ellanghiyil S, Kuttan G and Kuttan R: Induction of apoptosis of tumor cells by some potentiated homeopathic drugs: implications on mechanism of action. Integr Cancer Ther 11: 172-182, 2012.

30. Bishayee K, Paul A, Ghosh S, Sikdar S, Mukherjee A, Biswas R, Boujedaini N and Khuda-Bukhsh AR: Condurango-glycoside-A fraction of Gonolobus condurango induces DNA damage associated senescence and apoptosis via ROS-dependent p53 signalling pathway in HeLa cells. Mol Cell Biochem 82: 173-183, 2013.

31. Huschtscha L, Bartier W, Malmstrom A and Tattersall M: Celldeath by apoptosis following anticancer drug-treatment in vitro. Int J Oncol 6: 585-593, 1995.

32. Gu B and Zhu WG: Surf the post-translational modification network of p53 regulation. Int J Biol Sci 8: 672-684, 2012.

33. Bulavin DV, Saito S, Hollander MC, Sakaguchi K, Anderson CW, Appella E and Fornace AJ Jr: Phosphorylation of human p53 by $\mathrm{p} 38$ kinase coordinates N-terminal phosphorylation and apoptosis in response to UV radiation. EMBO J 18: 6845-6854, 1999.

34. Sanchez-Prieto R, Rojas JM, Taya Y and Gutkind JS: A role for the p38 mitogen-activated protein kinase pathway in the transcriptional activation of p53 on genotoxic stress by chemotherapeutic agents. Cancer Res 60: 2464-2472, 2000.

35. Oda K, Arakawa H, Tanaka T, Matsuda K, Tanikawa C, Mori T, Nishimori H, Tamai K, Tokino T, Nakamura Y and Taya Y: p53AIP1, a potential mediator of p53-dependent apoptosis, and its regulation by Ser-46-phosphorylated p53. Cell 102: 849-862, 2000.

36. Kim H, You S, Farris J, Foster LK and Foster DN: Posttranscriptional inactivation of p53 in immortalized murine embryo fibroblast cells. Oncogene 20: 3306-3310, 2001. 